\title{
So you want to be an academic researcher in business and management studies! Where do you start and what are the key philosophical issues to think about?
}

\author{
Dan Remenyi \\ Department of Information Systems, University of the Witwatersrand, Private Bag X1, Wits, 2050 Republic of South Africa \\ 035DANS@MENTOR.EDCM.WITS.AC.ZA \& 100345.427@COMPUSERVE.COM
}

Accepted March 1996

\begin{abstract}
The most important step an academic researcher takes is establishing a methodological framework in which to conduct the research. This step is difficult because there are a wide number of options available and because established researchers often argue passionately for their own particular approach. In this article I discuss the important philosophical questions of why research. what (and where) to research, and how to research. I go on to discuss the main methodological frameworks available to the business and management researcher, and suggest an approach whereby a masters or doctoral student can make a considered decision as to which is best for his/her research. In the article I also suggest a practical approach as to how to conduct a research programme for a higher degree.
\end{abstract}

\section{Introduction}

The aim of this article is to discuss the philosophical issues which are necessary to consider when undertaking academic research into business or management. The article also considers the research options or paradigms available and suggests how a researcher can make an informed and sensible decision as to how to proceed.

The starting point in all research undertakings is to focus clearly on the fact that the objective of this activity is to add something of value to the body of accumulated knowledge and in this case accumulated business and management knowledge. This means that an unanswered question or unsolved problem will be identified and studied and that the researcher will attempt to produce a suitable answer or a solution or illustrate a specific area. Of course the focus here is on difficult problems to which the solution is not obvious and which when solved will add material value to the subject area being studied.

There are at least three major philosophical ${ }^{1}$ questions which should be addressed at the outset of the research. These are: why research, what to research, and how to research? It could also be argued that where to research, and when to research, although perhaps of lesser philosophical importance, also deserve attention. In addition there is the question of research ethics (Remenyi \& Williams, 1995).

It is important to understand why it is necessary to be concerned with these philosophical questions. A researcher has to be able to convince an audience that by his/her research efforts something of value ${ }^{2}$ has been added to the body of knowledge. This audience is usually very critical, being composed of examiners, funders or colleagues. In addition the academic researcher needs to explain why the research should be considered important; needs to point out precisely what was found and what use the findings are to the community, as well as be able to state clearly the basis of the claim of adding something new of value to the store of knowledge. Sound answers to these questions rely on the philosophical underpinning of the research process. Academic research into business and management issues need to be contrasted with commercial research or intelligence. Unlike the former, the latter is about accessing already established knowledge and presenting it in a more accessible manner for the purposes of decision making.

\section{Why research?}

There are two levels at which the question of 'why research?' should be considered. At the first level, which is rather obvious, the need to research is related to the fact that there are many issues and subjects about which we have very incomplete knowledge. Although there are examples of this in every discipline, in business studies there are perhaps even more unanswered questions than in many other areas of study due to the fast changing nature of the subject. The relationships between markets and products; the relationships between financial structures and corporate performance; the relationships between individual performance and corporate structure and the relationships between information technology and effectiveness are but a few areas which need exploring to enhance general comprehension. In fact, business studies is sometimes said to lack a rigorously formulated body of knowledge and this view is clearly supported by Pascale who suggests that:

'Even today's most careful students of organisations will readily admit that they lack adequate models to predict ${ }^{3}$ corporate success. Recall how widely we celebrated such New Age cultures as People Express, Atari, and Rolm. Ardent supporters include academics, consultants, business journalists, and seasoned executives. Our former enthusiasm becomes a source of embarrassment ${ }^{4}$ when we hold ourselves accountable for predictive accuracy.

It is no longer permissible to dismiss these reversals lightly, acknowledging once again that "management is an art", and excusing ignorance by giving it another name. The sobering truth is that our theories, models, and conventional wisdom combined appear no better at predicting an organisation's ability to sustain itself than if we were to rely on random chance' (1990: 22).

The second aspect of the need to research is related to homo sapiens' compulsion for growth. There appears to be an endless requirement for increased performance in all aspects of life. Bigger and faster aeroplanes are required. Greater athletic performance is demanded of sports people. Better health care is actively sought. More profits are demanded of business houses etc. In a similar way society understands that knowledge is power and therefore there is the need to continually break the frontiers of knowledge through the 
research process. In fact it is hoped that the acquisition of more knowledge will directly or indirectly lead to the greater good of the society at large. Thus billions of dollars are spent annually on research into a wide range of subjects affecting the daily lives of the population.

Of course academic research may be conducted to obtain a degree which may be an end in its own right or it may be to acquire a qualification for a particular employment opportunity. Research is conducted by university teachers in order that they might be confirmed in their posts as well as to satisfy a compulsion to be at the leading edge of their subject.

There is however a dark side to research. As knowledge is power it can be misused. Although genetics can help cure many diseases it can also be used to identify the sex of the unborn in order to allow the termination of unwanted foeti. Genetics can be used to help resolve paternity or maternity suits, but in the hands of regimes such as the old South African apartheid system it could be used for unacceptable racial classification. Knowledge of information systems can be used to help organizations become more efficient and effective, but it can also be used to impose punitive work regimes on the staff. Information technology can enrich certain parts of the society while putting many thousands of white and blue collar workers out of a job. Science, which is often regarded as nothing more than another word for knowledge, has been described by Collins \& Pinch (1994) as a Golem. A Golem is a very powerful but very clumsy slave which must be used with considerable caution.

But on balance research is a most exciting, stimulating and rewarding activity which many masters and doctoral students report as being the best part of their educational experience.

\section{What (and where) to research?}

The questions: 'what to research?' and 'where to research?' are very closely related. Clearly it is not sensible to expect an institution which has little or no expertise in a discipline to be able to support a research initiative in that area or field of study and thus an aspirant researcher should look for an appropriate location at which to pursue his/her scholarly works.

Assuming an institution with adequate competence in the business and management environment, the answer to the question of what to research, is at first glance obvious. For business and management researchers, issues related to improving the efficiency and effectiveness of the business and management process are the main focus of what should be researched. However this is too general to be of much value to any aspirant researcher.

Every would-be researcher will most probably have undertaken a previous course of study in which a subject or discipline will have been studied to some considerable depth. This may have been achieved by an undergraduate degree in economics, sociology, psychology or accounting, to mention only a few possible options. It may also have been achieved without a degree, through many years of working experience, especially where the individual has made a definite effort to keep up with the latest thinking in the field by reading the appropriate literature. These studies and/or experiences will have provided a strong base on which to build a research programme. However, as well as in-depth knowledge of the sub- ject, the aspirant researcher should also be widely read in order to put the discipline into context as well as to look for interdisciplinary linkages and connections.

Nonetheless it is generally considered advisable, although not essential, for an aspirant researcher to work closely to the original discipline studied. Although it is not impossible to change disciplines for a masters or doctorate degree, such a change implies a very substantial amount of work for the candidate to become up-to-date with the subject matter and acquire sufficient familiarity with the relevant body of academic thinking.

In addition to the researchers own competence is the issue of the expertise of the chosen institute and the possible supervisors therein. Few aspirant researchers have a high degree of freedom as to where they will research. Usually personal finance, convenience of location or previous academic pedigree dictate the institute or institutes which will accept the researcher. With these constraints in mind it is vital for the aspirant researcher to get to know the faculty in order to establish their research interests as well as their strengths and weaknesses. In addition to these relatively objective issues there is the question of personal. chemistry between researcher and supervisor. It is usually sensible for there to be some degree of empathy between these parties. In fact there is a school of thought which suggests that the aspirant researcher should primarily concentrate on finding a suitable mentor and be prepared to accept a research topic recommended by him/her.

Whether or not such a personality-orientated approach is adopted it is most important for the researcher to find a research field in which the faculty has expertise and interest. This process can take time and it certainly should not be rushed. Far too many researchers begin with the notion that they would like to study a subject which is of no interest to any member of the faculty and for which there is little expertise in the institute. When this happens and the new researcher insists on continuing with the chosen subject, the risk profile of the research and subsequent likelihood of obtaining a degree is substantially elevated. In simple terms such circumstances frequently lead to failure.

Another important issue concerning what should be researched, relates to constraints imposed by money and time. Clearly some research topics will take much longer than others and they can also consume a very significant amount of funds. For example, a study of airline reservation systems as strategic devices would probably require a research candidate to collect evidence from a number of international air carriers around the world. It could be argued that such a study would require visits to American Airlines, Delta, United, British Airways, Swissair and Singapore Airlines and collecting data for such a research project would require sizeable funds and a long period of lapsed time. Masters and doctoral students most frequently do not have an abundance of either time or money and therefore relatively modest projects should be undertaken. This does not detract from the notion that such research must deliver material value resulting in a new way of looking at a problem. It is important for the newcomer to research to understand that a relatively small project can lead to very rich insights and thus make a substantial contribution to the body of knowledge. Even doctoral research 
which clearly must be original, relevant and make a material contribution, need not be in the Nobel prize winning category!

In general terms business research is frequently aimed at helping to develop management understanding of how business organizations work. It is frequently suggested that the best business research should deliver guidelines by which individuals in positions of responsibility can manage their business responsibilities more efficiently and effectively.

\section{How to research}

At the outset it is important to appreciate that the nature of the research process is often relatively unstructured and is frequently unpredictable. It is sometimes described as a voyage of discovery during which the researcher learns much about the subject being researched as well as research methodologies and perhaps even about himself or herself.

One of the major concerns of the researcher is to deliver a convincing or at least a credible answer or solution which will be accepted by his or her peers and thus it is important for the researcher to be able to convince that audience that the approach to the research has been sound. ${ }^{5}$ This requires an understanding of the nature of the processes required to create knowledge.

To claim that a valuable or significant addition has been made to the collection of knowledge, the researcher should comply with the scientific method, ${ }^{6}$ that is an informal but strict set of rules that have evolved to ensure the integrity, reliability and reproducibility of the research work. This is not easy because there are almost as many definitions of science ${ }^{7}$ as there are scientists. In fact 'scientists have not yet settled among themselves on a single model of what science is' (Lee, 1989).

But perhaps the most succinct and useful definition of science is the following offered by Einstein :

'Science is the attempt to make the chaotic diversity of our sense-experience correspond to a logically uniform system of thought. In this system single experiences must be correlated with the theoretical structure in such a way that the resulting co-ordination is unique and convincing' (1950: 98).

However Einstein does not tell us how this order in our understanding of the world is to be brought about, and it is as well to begin with a caution from Born:

'There is no philosophical high-road in science with epistemological sign-posts. No, we are in a jungle and find our way by trial and error, building our road behind us as we proceed. We do not find sign-posts at cross-roads, but our own scouts erect them to help the rest' (1950: 99).

To complicate matters further the process of carrying out research is itself highly subjective, depending on the intuition and the inspiration of the researcher. In the words of Gould:

'Science is not an objective, truth-directed machine, but a quintessentially human activity, affected by passion, hopes, and cultural biases. Cultural traditions of thought strongly influence scientific theories' (1980: 225).
Bearing in mind these cautions and warnings, it is nevertheless possible to develop some guidelines which those engaged in research may find useful and may wish to follow.

\section{Research methodologies in perspective}

Before discussing the guidelines available to those wishing to engage in business and management research it is useful to put the issue of research and its methodologies into perspective.

\section{Research into the physical and natural world}

Research into the physical and natural world is an ancient human activity. Its roots go back before recorded time. It is reasonable to speculate that the first researchers were active perhaps 10000 years ago. By somewhere about $7000 \mathrm{BC}$ our pre-historic researchers had learnt something about agriculture and maybe animal husbandry. Some time after this date, about 2000 years later, our ancestors had begun to work out for themselves the rudiments of architecture, and by about $3000 \mathrm{BC}$ some early forms of cities begin to appear. Although a substantial body of knowledge had been accumulated by this stage in human development it is probably correct to say that the more formal scientific process really should be considered to have begun in earnest at the time of the Golden Age of ancient Greece around about $600 \mathrm{BC}$ (McKeon, 1994; Trundle, 1994).

Unfortunately the scientific tradition in the western world cannot be regarded as having been continuous from this date. For a number of hundreds of years, a period which is sometimes referred to as the Dark Ages, little if any serious research or science was undertaken. The roots of modern research can be regarded as dating from the experiments undertaken by Kepler (1571-1630), Galileo (1564-1642) and Newton (1642-1727) (Bynum, 1982). Thus, the modern physical sciences have had a solid tradition of experimental research, and largely experimental laboratory research, for some 300 to 400 years.

The result of this is that the methods of research into the physical and natural sciences are well understood and well agreed by such scientists. This is so much the case that the rules of scientific experiments are seldom explicitly taught to aspirant natural scientists. Those beginning a career as a research scientist in physics, chemistry, botany or even medicine learn the scientific method by practising well established experiments. In fact its methods have become internalized for the physical or natural scientist and thus novices are not taught explicitly but rather only by example. Research scientists and research engineers are so close to their research methodology that they seldom discuss it as part of their post graduate degrees. They argue that if methodology has to be taught, it is then, by definition, suspect. These physical and natural scientists focus on the fact that their work should show how the issues being studied play a part in the greater scheme of the universe and how their findings are generalizable.

This approach reflects their conviction in the correctness of their research methodologies which have been developed over a period of hundreds of years. This is not quite the case in the social sciences. 


\section{Research in the social world}

Although it is clear that the ten commandments of the JudeoChristian faiths, dating back some 3000 years, are a social charter needed to keep a society together, and were thus most probably the result of some research. Also the forms of government adopted in ancient China, Egypt and Greece, to mention only three civilisations, are undoubtedly the product of political and social enquiry. In addition outstanding contributions to social science have been made by Plato, Aristotle, Saint Augustine and Thomas Aquinas and many others through the ages. Nontheless social science in any rigorous sense is perhaps only in the order of 200 years old. In fact it might be argued that modern social science is a phenomenon of the twentieth century and thus has less than 100 years experience behind it. Of course research into business and management is even more recent with the Hawthorne (Parsons, 1992) experiments in the late 1920s and early 1930s probably being one of the first structured business research studies.

Because research into business and management is so relatively recent there is much concern about the validity of the methods used by its practitioners and thus much attention is given to the methods employed to justify the claim that something material and valuable has been added to the body of accumulated knowledge. As a result research methodology is explicitly taught to those undertaking business and management studies.

Furthermore any material research in business or management, such as that undertaken for a masters or a doctoral degree, requires that the methodology used be clearly spelt out, perhaps in a chapter of its own (Remenyi, 1990), so that the results of the research are convincing or at least credible. This care and attention to methodology reflects the social scientists lack of conviction, at least in a relative sense to the natural scientists, of the correctness of their methodologies. ${ }^{3}$ This attention to methods is especially true when more sophisticated techniques which go beyond traditional experiments are being employed by business and management researchers. After all, little was added to the body of knowledge through simple experiments like those carried out at Hawthorne where the intensity of the factory lighting available to the shop floor staff was altered and changes in the staffs productivity was recorded. More sophisticated methods are required to add to the understanding of the complex issues in business and management.

Some physical and natural scientists argue that social science is not real or proper science because the work of the social scientist seldom results in developing general laws which are robust under a wide variety of situations. This view is generally regarded, especially by social scientists, as being misinformed. Firstly, the laws developed by the physical and natural scientists are not as general as they sometimes claim. and secondly, a degree of generality is intrinsically built into the laws developed by the social scientist even when generalization is not a key issue. This occurs because once a phenomenon has been identified, even only once, the probability of it being unique is so low as to make it almost impossible. In fact there is a growing confidence among social scientists that their work is fully scientific and that in some cases the traditional physical and natural scientists are actually being left behind because of their reluctance to consider new ways of thinking about scientific methods.

\section{Empirical versus theoretical research}

There are many different taxonomies of research approaches. One of the most commonly used is that which differentiates research into empirical or theoretical studies. Empirical is defined by the Shorter Oxford English Dictionary as 'based on, or guided by, the results of observation or experiment only', while it defines theoretical as 'contemplative, of the mind or intellectual faculties'.

Modern empiricism is regarded to have begun with John Locke's (1632-1704) clear attack on metaphysics in his essay 'Concerning human understanding', published in 1690.

A large amount of academic research conducted today is based on empirical techniques.9 This is true for both the physical and natural world as well as the social world. The rationale behind this bias for empiricism is a philosophical assumption that evidence, as opposed to thought or discourse, is required to be able to make a satisfactory claim to have added to the body of knowledge. Of course it is not always easy to collect usable evidence which can lead to believable results (Millar, 1994). In addition the assumption that evidence is the only route to good research or science is by no means universally accepted.

To understand the philosophical argument of the need for evidence, it is necessary to appreciate that these two approaches to research are sometimes held up as being the two poles which represent the opposite ends of the two major cultures of research. The empiricist goes out into the world and observes through experiment or perhaps just by relatively passive observation what is happening. As a result of studying these observations and collecting evidence related thereto, and then drawing conclusions therefrom, a claim is made that the researcher has added to the body of knowledge.

On the other hand, the research theorist studies the subject through the writings of ethers and through discourse with learned or informed individuals who can comment on the subject area, usually without any direct involvement in observation of behaviour and the collection of actual evidence. The theorist reflects on these ideas and using his/her intellectual capabilities constructs another or different view of the situation which sometimes may be regarded as a new theory. At the end of the theorists work, conclusions are also drawn and a claim is made that the researcher has added to the body of knowledge.

Although it is clear that these two approaches to research are quite different they are both regarded by a very large number of scientists as perfectly acceptable methods for adding value to the body of knowledge.

If there is any problem in focussing on these two categories of research it is in the fact that it is not particularly useful to think of them as being entirely distinct and being poles apart. In fact in a special sense they are totally intertwined with each other. It is not possible to be an empiricist without having a thorough understanding of the theoretical issues surrounding the subject which will be studied, and about which evidence will be collected. It is well accepted that what is observed is often and largely a function of what is believed and a paradigm or theory may be defined as what is believed. Thus 
empirical research must be fundamentally rooted in theory and it is in fact impossible to conduct such research without the researcher taking a specific theoretical standpoint.

On the other hand theoretical research, although not directly based on evidence collected from observation, also relies on ideas which have at some previous point been based on specific observations or original evidence collected by means of empirical work. In simple terms theoretical research does not occur in a vacuum. It is rather the result of thinking about the findings of previous empirical research as well as theoretical work.

Some scientists regard the relationship between theoretical and empirical work to be difficult and they are especially concerned about how theory and data relate to one another, which they describe as a dilemma. This dilemma is sometimes stated as the problem of which comes first, data ${ }^{10}$ or theory. The proposition is that theory cannot be generated without data and data cannot be collected without a theoretical framework. This is a persistent dilemma which is probably not resolvable and is sometimes referred to as the paradox of data and theory. In practise, there is a sort of symbiotic relationship between these two aspects of research which reinforce each other. There are always theoretical assumptions associated with the collection of evidence and there are always evidence dimensions underpinning theory.

Thus, in general far too much is made of the distinction between empirical and theoretical research as both are central to any significant research activity and both are actually required to make any real scientific progress.

Empirical research is the dominant research paradigm in business and management research. Theoretical research plays a lesser role today and it would be difficult, although not impossible, to obtain a senior degree from a major university on the basis of a theoretical research paradigm alone.

Empirical research is frequently associated with a positivist view which has sometimes been described as a tough minded approach to facts and figures, derived from the physical and natural sciences. This view is not actually correct as empiricism can be either positivist or phenomenolugist in nature.

\section{Characteristics of a positivist}

Being a positivist, or more correctly a logical positivist, implies that the researcher is working with an observable social reality and that the end product of such research can be the derivation of laws or law-like generalizations similar to those produced by the physical and natural scientists.

Positivism came into its own with the work of Auguste Comte (1798-1857) who outlined an approach to positivism in his Course in positive philosophy, published in six volumes between 1830 and 1842 .

This philosophical stance or paradigm sees the researcher as an objective analyst and interpreter of a tangible social reality. Some of the assumptions underlying positivism are independence of the researcher from the researched, determinism, that is there are causes and effects, the criticality of evidence, parsimony and the ability to generalize or model, especially in the mathematical sense of modelling. The emphasis of positivism is on quantifiable observations which lend themselves to statistical analysis.

\section{Falsification and paradigm shifts}

An important aspect of the positivist approach to research is the concept of falsification which was first articulated by Popper (1975) who pointed out that it was impossible to prove a theoretical conjecture through the process of induction." Popper argued that no matter how many $\propto$ casions on which a proposition or phenomenon is observed. these observations cannot be regarded as proof of the generalizability or universality of the proposition or phenomenon. The example which is frequently used to explain this is related to the swan. Thousands or hundreds of thousands of swans observed in Europe could lead a researcher, who was practising the research notion of induction to the belief that all swans were white, and this mistaken view could remain intact until someone visited Australia and encountered a black swan.

Popper pointed out that a more scientific approach than induction to theory confirmation was the notion of falsification. By the practice of falsification is meant that researchers should look for evidence to reject their theoretical conjectures and thus try to show that they are false. In fact some scientists argue that if a conjecture is by it nature not falsifiable, then it is not a scientific conjecture. Thus some would say that the theory of evolution is not strictly scientific as it cannot be falsified. Furthermore, according to Popper, once a theory has been falsified it should be immediately rejected and removed from what was considered to have been the body of knowledge. If researchers cannot find evidence to falsify their conjectures then the theory is accepted as valid pro-temp, that is until some other researcher can falsify it. This position certainly emphasize the tentative nature of all our knowledge which has been evidenced by the rejection of many theories during the pass four hundred years. Although falsification is regarded as an important notion in research methodology, it is not without its critics.

Lakatos (1970) gave a comprehensive argument as to why falsification should be regarded with suspicion or at least be seen to have limited value in the establishment of knowledge, when he described how scientists attempt to explain evidence which contradicts their theories. He pointed out that when evidence contradicts established theory the first recourse of scientists is to argue that they have encountered an abnormality or exception to the general rule. This view is well supported by the quaint aphorism the exception proves the rule. Scientists faced with this type of situation generally try to extend or develop their theories so as to accommodate the new evidence. And this may be done a number of times without the original theory which has clearly been falsified, actually being rejected. Lakatos explains this when he tells a very realistic parable which is as follows:

'The story is about an imaginary case of planetary misbehaviour. A physicist of the pre-Einsteinian era takes Newton's mechanics and his law of gravitation, (N), the accepted initial conditions, (I), and calculates, with their help, the path of a newly discovered small planet, p. But the planet deviates from the calculated path. Does our Newtonian physicist consider that the deviation was forbidden by Newton's theory and therefore that, once established, it refutes the theory N? No. He suggests that there must be a hitherto 
unknown planet $q$ which perturbs the path of $p$. He calculates the mass, orbit, etc. of this hypothetical planet and then asks an experimental astronomer to test his hypothesis. The planet $\mathrm{q}$ is so small that even the biggest available telescopes cannot possibly observe it: the experimental astronomer applies for a research grant to build a yet bigger one. In three years time the new telescope is ready. Were the unknown planet $q$ to be discovered, it would be hailed as a new victory for Newtonian science. But it is not. Does our scientist abandon Newton's theory and his idea of the perturbing planet? No. He suggests that a cloud of cosmic dust hides the planet from us. He calculates the location and properties of this cloud and asks for a research grant to send up a satellite to test his calculations. Were the satellite's instruments (possibly new ones, based on a little tested theory) to record the existence of the conjectural cloud, the result would be hailed as an outstanding victory for Newtonian science. But the cloud is not found. Does our scientist abandon Newton's theory, together with the idea of the perturbing cloud and the cloud which hides it? No, he suggests that there is some magnetic field in that region of the universe which disturbed the instruments of the satellite. A new satellite is sent up. Were the magnetic field to be found, Newtonians would celebrate a sensational victory. But it is not. Is this regarded as a refutation of Newtonian science? No. Either yet another ingenious auxiliary hypothesis is proposed or the whole story is buried in the dusty volumes of periodicals and the story never mentioned again. (At least not until a new research programme supersedes Newton's programme which happens to explain this previously recalcitrant phenomenon. In this case the phenomenon will be unearthed and enthroned as a crucial experiment.)' (1970: 100-100)

This notion of theory retention fits in neatly with the ideas of Kuhn (1970) and paradigm shifts. Kuhn argues that most researchers spend their time puzzle solving. By this he means that researchers frequently spend much, if not most, of their effortsn solving problems within a particular framework or paradigm. This is hardly surprising as paradigms, theories or mind sets are the basic building blocks on which researchers work. However, Kuhn points out that occasionally research leads to a paradigm shifting and thus a revolutionary breakthrough in thinking occurs. Perhaps this could be when falsification is finally accepted and the old theories and conjectures are thrown away. Kuhn argues that paradigms are disposed off by a sharp revolutionary shift in thinking. However, like Popper, although this idea is an important one in research methodology, it is not without its critics who claim that paradigms crumble rather than abruptly shift, sometimes very slowly, under the weight of contradictory evidence rather than go though a revolution. Certainly according to Collins (1995) new theories are generally not the product of flashes of instant genius but rather the result of carefully articulated and thoroughly debated thought.

\section{Phenomenology}

The positivist approach to research needs to be contrasted with the phenomenological approach. According to Cohen \& Manion:

'Phenomenology is a theoretical point of view that advocates the study of direct experience taken at face value; and one which sees behaviour as determined by the phenomena of experience rather than by external, objective and physically described reality' (1987: 151).

The phenomenological school of thought is regarded to have been launched by Franz Brentano (1838-1917) and developed by Edmund Husserl (1859-1938) who set out the basic methods of phenomenology in his work Logical Investigations. Unlike the positivist, the phenomenologist ${ }^{12}$ does not consider the world to be objective but instead focusses on the primacy of subjective consciousness. Each situation is seen as totally unique and its meaning is a function of the circumstances and the individuals involved. To the phenomenologist ${ }^{13}$ the researcher is not independent of what is being researched but is an intrinsic part of $j$ t. The world is not essentially deterministic, but rather stochastic, and parsimony is not a central issue. The phenomenologist believes that the world can be modelled, but not necessarily in a mathematical sense. A verbal or diagrammatic or descriptive model could be acceptable.

To use a phenomenological approach the researcher has to look beyond the details of the situation to understand the essences working behind them. The researcher constructs a meaning in terms of the situation being studied. Furthermore the phenomenologist understands that the world is not composed of a single objective reality, but rather is composed of a series of multiple realities, all of which should be understood and taken into account. Each reality is an artefact in its own right. It is generally of little interest to the phenomenologist that his or her work will not lead to law-like generalizations in the same sense as that of the positivist. Thus for the phenomenologist the world is socially constructed.

This research paradigm is sometimes described as the descriptive/interpretative approach which believes that every event studied is a unique incident in its own right. In this school of thought there is nothing else other than phenomena and the essence of a phenomenon is understood intuitively. It is not usually possible or desirable to spell out a priori the steps in a phenomenological study in the same way as one can for a positivist research programme. The approach to phenomenology unfolds as the research proceeds. Early evidence collection suggests how to proceed to the subsequent phase of evidence collection, as does the interpretation of the evidence itself. Rich or thick descriptions are sought which are the building blocks of the argument that the researcher then develops.

Although this point is not universally accepted, it is sometimes believed that this type of research is not readily conducive to generalizations other than the type which states that as the phenomenon has been shown to exist or occur at least once it is most probable that it will exist or occur again. This is a fairly popular research paradigm in social science which is of growing importance in the business and management arena and is sometimes referred to as Hermeneutics. 
Once a researcher has made a choice between empiricism and phenomenology it is not uncommon for there to be a fervent adherence to the approach chosen, often leading acrimonious debate.

\section{Differences and similarities between positivism and phenomenology}

It may be argued that positivism and phenomenology are not totally different in their impact on research and in the generalizability of their findings. This argument is as follows.

One of the key tenants of positivism is that it takes a reductionist approach to exploring the relationships between the variables being studied. This is necessary in order to be able to control an experiment or an investigation and thus be able to understand how the variables concerned are behaving. This reductionist approach must by its very nature lead to simplifications of the real world environment in which the variables naturally or usually exist. This simplification means that the results of positive research report on a situation or setting in which some of the complicating factors have been stripped out.

When the research has been concluded and the findings proclaimed they are at best an indication of how the real world will actually behave because they are based on a reduced set of variables. Thus these findings would not be per se generalizable to the real world until the research has been replicated a number of times. It is important that the replications are made by different groups of researchers, under different conditions and at different times (Wessley, 1994). Now each replication may be seen as the researcher taking another still photograph of the situation and this process is repeated until enough evidence has been collected to make some sort of generalization. In addition, because in reality the world is essentially not deterministic in any absolute sense, the results of repeated research will generally not produce identical results. Some sort of accommodation must be made for the presence of unexplained fluctuations in the results which are usually referred to as errors. Before the positivist's work will be accepted as a valuable addition to the body of knowledge, he/she must argue convincingly that the findings are valid and that the errors are random.

On the other hand a phenomenologist approach to research is not reductionist but holistic. This approach to research allows much more complicated situations to be examined. It involves itself not only in as many as possible of the variables being studied but also the context of the study. Thus, part of the context of any research study is the nature of the researcher and the characteristics of the setting. These issues are included in a phenomenological study, while they would be removed from a positivist study. At the end of the research study the phenomenological researcher has also produced a still photograph of the variables being studied. Although this photograph is much more sophisticated than the one obtained by the positivist it achieves approximately the same result. It is one view of a set of variables. Like positivist research, such a study needs to be replicated before any law-like generalizations can be made.

By definition, it is more difficult to replicate such holistic studies. Generalizations are much more problematical. Nonetheless similar studies may be undertaken and if these studies produce consistent findings which support an emerging theory, it may be granted some degree of general validity. Under these circumstances there is likely to be much greater variation in the results of different studies and thus a higher degree of error. However, in exactly the same way as with the positivist, before the phenomenonlogist's work will be accepted as being a valuable addition to the body of knowledge, he/she must argue convincingly that the findings are valid and that the errors are random.

Sometimes a distinction is made that the positivist's findings can be modelled, whilst the phenomenologist's findings cannot. This view is a misunderstanding of the concept of a model. A map of the world is no less a model than is $y=m x+c$, which is the model of a straight line. Admittedly the positivists model is more likely to be expressed mathematically than the phenomenologists, which is usually expressed either in words or in diagrams. But both are models and are capable of being used to explore different assumptions.

However, ultimately perhaps the only really significant difference between positivist and phenomenological research is the degree of error which needs to be explained and thus accommodated.

Collins provides an interesting insight into this process when he says,

'It is important to note that there is always a judgement to be made. That scientific discoveries are not made at a single point in time and at single places and with single demonstrations. They are made through a process of argument and disagreement. They are made with the scientific community coming slowly toward a consensus' (1994).

Thus whether a positivist approach or a phenomenological approach is being employed the researcher can expect to have to strongly argue for his/her case as it is unlikely that it will be readily accepted without a convincing set of reasons.

Seeing positivism and phenomenology as closely related concepts instead of being two distinctly different poles on a continuum is useful. This view, together with the understanding that empirical and theoretical research are also not distinct poles on a continuum, helps to see research methods as a pool of tools or research directions from which the researcher may draw appropriate help as and when required. This approach to understanding these difficult issues of empiricism, theoretical research, positivism and phenomenology could allow these methodologies to be mixed and matched from a triangulation perspective in order to help validate findings, even within one research project.

\section{Different approaches to research}

Besides the empirical-theoretical classification there are many other different ways of describing research methods. Galliers (1991) provides a list of such approaches in the context of information systems research, a subset of which has been reproduced in Table 1 . It is not suggested that this taxonomy is exhaustive nor that all of these approaches are particularly suitable to all types of business and management researchers who may actually have to operate under a number of restrictions. However it is a useful list for the purposes of extending this discussion within the limits of a article. 
Table 1 Some approaches to research as described by Galliers

\begin{tabular}{lccccc}
\hline & & & \multicolumn{3}{c}{ Galliers } \\
$\begin{array}{l}\text { Researchers/ } \\
\text { approaches }\end{array}$ & $\begin{array}{c}\text { Van Horn } \\
(1973)\end{array}$ & $\begin{array}{c}\text { \& Ives } \\
(1982)\end{array}$ & $\begin{array}{c}\text { Vogel \& } \\
\text { Wethbe } \\
(1984)\end{array}$ & $\begin{array}{c}\text { Galliers \& } \\
\text { Land (1987) }\end{array}$ & $\begin{array}{c}\text { Farhoom- } \\
\text { and } \\
(1987)\end{array}$ \\
\hline $\begin{array}{l}\text { Laboratory } \\
\text { experiments }\end{array}$ & $* 14$ & $*$ & $*$ & $*$ & $*$ \\
Field experiments & $*$ & $*$ & $*$ & $*$ & $*$ \\
Surveys & $*$ & $*$ & $*$ & $*$ & $*$ \\
Case studies & $*$ & $*$ & $*$ & $*$ & $*$ \\
Action research & & & & $*$ & \\
Longitudinal & & & & & $*$ \\
$\begin{array}{l}\text { Forecasting' } \\
\text { futures research }\end{array}$ & & & & & $*$ \\
Simulation & & & & & $*$ \\
\hline
\end{tabular}

This list may be considered as a set of research tools which is available to the aspirant researcher. $\mathrm{It}$ is therefore important for the researcher to be familiar with these tools as they will determine the routc to evidence collection, evidence analysis and theory generation. A researcher may use one or more of these tools on different facets of the research work to get closer to producing a convincing argument.

\section{Laboratory experiments}

In the first place although laboratory experiments are available to business and management researchers, they are not of much use in practice in these disciplines except in very limited or specific circumstances. In general the issues which are of interest to business and management researchers cannot be studied in laboratory settings. Organizations and even individual managers will not usually collaborate with such experiments.

Laboratory experiments are nonetheless sometimes employed to answer very specific questions such as how certain decisions are made concerning various aspects of managerial choice. This approach is sometimes also used to explore an idea before embarking on a major survey or case study project. In business and management research, laboratory experiments are used far more frequently in the United States of America, using students as surrogates for managers, than in other parts of the world (Tung \& Heminger, 1993).

\section{Field experiments}

Field experiments are more common than laboratory experiments in business and management research. The famous Hawthorne studies were classical field experiments which provided insight into worker productivity issues. However, there are definite limits to how important a question can be addressed through this research technique. For example it is not usually possible to persuade an organization to deploy a computer system as a field experiment so that researchers may study its impact on efficiency or effectiveness. Nor is it usually possible for a researcher to convince an organization to change a material part of its policy for such reasons. Similarly, it is seldom the case that an organization will change its marketing alliances in order to understand how this policy change will effect the market. However a type of field experiment may be conducted around a required change of policy or a new investment. Here the motivation of the organization is to achieve an enhanced business result and the researcher simply observing the phenomenon. Thus field experiments do have an important role in business and management research when the right circumstances are present.

However, in general, business and management studies research is no longer largely or even substantially experimental, either laboratory or field, but rather based on observation of actual business and management functions as they happen or as they have happened. In the disciplines which constitute business and management studies, experiments are frequently regarded as too artificial and thus remote from. the business and management world to be of any real applicability.

\section{Survey}

Surveys are a very common approach to research in business and management. Surveys which are defined for the purpose of this article to be composed of questionnaires, offer an opportunity to collect large quantities of data or evidence (Oppenheim, 1966). Questionnaires allow evidence to be gathered concerning how much or how long or when, but are not really of great value when the researcher is asking about how or why. Thus as a general rule the nature of the evidence which may be collected by means of a questionnaire is often regarded as relatively superficial, especially in comparison to the evidence from which it is possible to collect other techniques such as case studies or personal interviews.

\section{Case studies}

The case study methodology is a way of establishing valid and reliable evidence for the research process. It is a research strategy for the social scientist in a similar sense as experiments are a research strategy for the natural scientist (Kasanen \& Suomi, 1987; Smith, 1990; Jocher, 1928/29). Yin states that:

'a case study from a research strategy point of view may be defined as an empirical inquiry that investigates a contemporary phenomenon within its real life context, when the boundaries between phenomenon and the context are not clearly evident, and in which multiple sources of evidence are used. It is particularly valuable in answering who, why and how questions in management research' (1984: 23).

According to Bell (1987) the case study methodology has also been described as an umbrella term for a family of research methods having in common the decision to focus on an inquiry around a specific instance or event. The philosophy behind the case study is that sometimes only by looking carefully at a practical, real life instance can a full picture be obtained of the actual interaction of variables or events. The case study allows the investigator to concentrate on specific instances in an attempt to identify detailed interactive processes which may be crucial, but which are transparent to the large scale survey. Thus it is the aim of the case study to provide a three dimensional picture of the situation. It can illustrate relationships, corporate political issues and patterns of influence in a particular context. 
Case studies are a very important approach for business and management researchers and much masters and doctoral research work is conducted using this method.

\section{Action research}

Action research usually involves a small scale intervention on the part of the researcher in the phenomenon being studied. Thus in this research paradigm the researcher becomes actively involved with the situation or phenomenon being researched (Aguinis, 1993; Ledford \& Mohrman, 1993).

Action research is participatory and very specific. An important feature of action research is that it is self-evaluative. It is most important for this type of research for the researcher to be aware of the impact which his/her presence has on the situation. Depending on the circumstances, quantitative or qualitative analytical techniques may be required to analyse the evidence being collected. This approach which is also sometimes referred to or closely related to participant observer research, is relatively new but its popularity is increasing.

\section{Longitudinal research}

Because business and management research is frequently focussed on finding out how and why phenomenon occur the snap shot view which, a one off collection of research evidence provides, is sometimes not enough. What is needed is evidence collected over a period of time so that the researcher may be able to discern how and why situations developed and how change occurs in these situations. This may be achieved through longitudinal research studies. Ideally longitudinal research studies are conducted over a considerable period of time, perhaps several years. Such studies will monitor the progress of a situation to see how it changes as a result of a series of developments or interventions over time (Pettigrew, 1985). Longitudinal research studies may sometimes be regarded as being similar to an extended field experiment where the subject of the study is being exposed to a number of extraneous variables in the environment.

This research paradigm is very powerful and can lead to a clear understanding of the issues at work in a given situation, but it is not extensively used in business and management research as the time period required will frequently extend beyond what is reasonable for a doctoral degree. In addition the cost of this type of study will often be prohibitive.

\section{Forecasting/futures research}

Forecasting research is often associated with regression and time series analysis (Collopy \& Armstrong, 1992; Sutrick, 1993). This technique allows projections to be made on the basis of past evidence. This is usually a highly quantitative approach to research. Futures research also looks ahead using techniques such as scenario projections and Delphi studies (McCarthy, 1992; Maital, 1993; Goldfisher, 1993). These approaches are generally not extensively used except in a number of specialized areas such as technology and finance.

\section{Simulation}

Simulation is the method used to investigate situations which do not readily lend themselves to a deterministic analytical treatment. Sometimes simulation can be used as a substitute for a laboratory or field experiment. Simulation is particularly relevant where there is a requirement for the evaluation of formal mathematical relationships under a large variety of assumptions (Freedman, 1992; Reiman, Simon \& Willie, 1992). There is not a very high degree of utilization of this research paradigm in business or management research except where mathematical modelling is a key part of the study.

\section{Getting started}

It is not sensible to decide on a research methodology too early in the research process. The research methodology should emerge as a result of the literature review and the debate between the aspirant researcher and his/her supervisor. Constraints of cost and time are also important in deciding on which specific research methodology is ultimately employed.

As mentioned above, probably most research in the business and management area will be empirical and much of this will have a positivist orientation, although it must be acknowledged that there is a growing interest in phenomenology. Although it is impossible to provide a general rule, it is probable that studies focussing on the hows and whys and whose objectives are to describe and understand general management issues, policy development and strategic deployments may require a more phenomenological approach than those studies considering the more functional aspects of subjects looking to predict and explain how disciplines such as marketing, operations management or finance actually work.

Some researchers will occasionally try to combine some aspects of positivism with some of the techniques of phenomenology. Thus the research could begin with case studies which are interpreted using hermeneutics and proceed with a broader validation using a survey and sampling approach.

Although a researcher should utilize these tools where they are most appropriate, frequently the choice of methods is a function of the background and education of the researcher. It would appear that those individuals who have scientific, engineering or mathematical education will tend to positivist approaches, whilst those with sociological or educational backgrounds will tend to phenomenology.

It may be said that there are five general phases to most research projects. These are the literature review, formalizing a research question, evidence collection, analysis of evidence, and developing conclusions.

Sometimes the most difficult part of any research project is finding the starting point. This is especially true when a phenomenological approach is being taken as a clear problem definition sometimes only emerges after extensive research has been completed. Once this has been achieved, much of what follows may be regarded as relatively routine, although it is true to say that good research always benefits from a substantial degree of creativity during each of its five phases and that few researchers will finish a major project such as a doctorate dissertation without encountering the occasional surprise.

\section{Literature review}

In the first instance the researcher should have some idea of the area in which the research is to be carried out. However it 
is quite important, at the outset of the research process, not to be too specific. Thus if the researcher wished to look at strategic information systems, for example, this would be specific enough at the very early stage of the research project. The next step is to review the literature in some detail. This means reading as much of the academically published material on the subject as possible. Thus the literature emphasis has to be placed on papers published in academically reviewed journals. The popular press and even textbooks should be given relatively low emphasis here. Of course it is sometimes the case that the topic is so new or novel that the popular press or videos have been used, but in such cases support for views expressed in these media should be found from experts in the field.

The literature review should indicate a suitable problem to research as well as giving the researcher some idea of the research methods or approaches which have been used in this field (Creswell, 1994). It is important to note that the literature should be critically evaluated and not just accepted on face value. It is this critical evaluation which may lead to a suitable research question.

By the end of the literature review the researcher should have a vision of what he/she wishes to achieve in their research. This vision should spell out the type of result which the researcher wants to achieve.

\section{Choosing the methodology}

There are many factors to be considered when choosing an appropriate research methodology. In the first place the literature review should reveal not only a suitable problem to be researched but also a suitable methodology which has been applied to this type of research question before. This certainly implies that the researcher is familiar with the range of methodologies available, as well as knowing something about their strengths and weaknesses.

The topic to be researched is one of the primary drivers to the choice of methodology. As a general rule precedent should be followed, although this may be abandoned if a suitable case can be made for a new methodological approach. The research culture in the institute is also an important determining factor, as is the skill and interest of the researcher's supervisor. Other stakeholders may also be influential such as the funders of the research.

A certain amount of business and management researchers use multi-methodologies. Thus for example case studies may be used to establish a grounded theory (Glaser \& Strauss, 1967), a survey may be used to confirm a theoretical conjecture and a longitudinal study may be employed to see if the effect of some action research is sustained. However, when this approach is taken, great caution needs to be exercised as multi-methodologies may lead to conflicting results. Also some researchers object to multi-methodologies because they suggest that in such situations, frequently none of the methodologies are properly or fully utilized. In addition some researchers regard the choice of a methodology as a fundamental philosophical statement about the researchers ontological and epistemological view point. If this is the case, then using more than one basic research methodology would be regarded as similar to trying to practise capitalism and communism simultaneously.
In practice the choice of methodology may change during the research project. It may be seen as a journey in which the researcher may develop from one paradigm to another as his/ her understanding of the research problem changes.

In choosing the research paradigm the researcher must be cognisant of the weakness of their preferred approach. They must be aware of the reaction of their stakeholders. But perhaps most of all they need to be able to satisfy their own ideological preferences.

Finally it is worth pointing out that the issue of time and money is most important, especially with regard to masters and doctoral research. Compromises will regularly have to be made between what would be ideal and what is practical.

\section{Formalizing a research question}

A comprehensive literature review should reveal problems or areas of incomplete knowledge in the field of interest. In fact most students, especially in the field of business and management studies, are swamped by possible research questions and often the supervisor has to work hard in convincing the student to reduce the number of research questions and to tighten their focus on a manageable problem. If the research problem is too wide the student will not be able to provide a satisfactory piece of research within a reasonable period of time or within the level of resources available to a doctoral or masters student.

These research areas will first manifest themselves as research problems which need to be reduced to a formal research question or series of questions in such a way that it is testable. This means that the question or questions need to be carefully framed in such a way that evidence may be collected which will allow a test to be carried out. For such a test quantitative evidence will normally be used although this may have been collected from relatively soft sources such as interviews or focus groups. To develop suitable questions the researcher will often have to have originally developed a theoretical conjecture and derived from this a set of either hypotheses or empirical generalizations.

\section{Evidence collection}

A suitable evidence collection strategy is required and the researcher may choose from a wide list of alternatives including those listed above, such as case study or survey, to mention only two.

In very broad terms there are two evidence collection strategies. These refer to the collection of quantitative and qualitative evidence. Quantitative evidence refers to numeric facts and figures such as stock market prices, wage rates, advertising expenditure to mention only three. These numbers may be collected from public domain sources or from the accounting or other records of individual organizations. Quantitative evidence is often regarded as objective or hard, although experienced researchers will readily point out that facts and figures are frequently much less objective than they first appear.

Qualitative evidence refers to opinions or points of view. These may often be very subjective although sometimes they may be supported by other sorts of evidence such as artefacts. Qualitative evidence is intrinsically more prone to bias than quantitative evidence and researchers have developed 
techniques such as triangulation's to help reduce the bias. However in the final analysis bias cannot be completely eliminated from the research process and research findings are probably best understood if the bias potential is clearly stated for all to see and to appropriately interpret. Furthermore the analysis of qualitative evidence is regarded to be more complex than the analysis of more quantitative evidence and there are several different techniques available to help in this respect.

In general, business and management researchers frequently ask questions related to how and why, and the evidence collection strategies which focus on these sorts of questions are qualitative in nature. These tend to be of more value to managers and executives than those questions which concern themselves with matters related to how much or when and who. Thus although some research questions lend themselves to qualitative data, many others require more quantitative evidence.

\section{Analysis of evidence}

Once the evidence has been collected it is necessary to conduct an analysis of it. The approach to evidence analysis varies enormously. It depends upon whether quantitative or qualitative evidence has been acquired. It depends upon the mathematical sophistication of the researcher.

Quantitative evidence will generally be analysed by the use of the statistics techniques. There are literally dozens of techniques available and the actual technique used will depend on the precise type of evidence collected. Many students find the use of statistics daunting. However, it is important to note that much statistical analysis may be performed with relatively little mathematical or statistical background. This is especially true today due to the user-friendly computerized statistically packages available and the easy to read statistical text books.

Qualitative evidence may be analysed, or perhaps it would be better to say interpreted, by means of a number of different approaches. Some of the techniques available for this purpose are actually qualitatively based such as content analysis or correspondence analysis. However other approaches are not reliant on quantitative thinking and these include hermeneutic or interpretative understanding of the evidence.

\section{Conclusions of the research}

Writing the conclusions is sometimes the most creative part of a research project. The conclusions must convince the reader that something of value has been added to the body of knowledge. As Collins (1994) points out, the conclusions deduced from the research need to be carefully argued in such a way that they will convince the research community, which in the case of masters or doctoral research, will be the supervisor and perhaps the funder.

The conclusions in business and management research should offer advice to practising managers as to how to conduct their business and management practices more effectively. It is usually considered that good research results are those which are put to use and which remain in use for some time. Bad or poor research results are either not used at all or are only used for a short period. The conclusion section of a dissertation will usually suggest some ideas for further research.

\section{Summary and conclusions}

It is necessary for a researcher to be concerned with a number of philosophical questions concerning why, what and how to research. This is because a researcher has to be able to convince an audience that by his/her research efforts something of value has been added to the body of knowledge. The researcher's audience is often highly critical, being composed of examiners, funders or colleagues. Sound answers to these questions rely on the philosophical underpinning of the research process.

Selecting and using a research methodology is not a simple matter for the business and management researcher. There is a considerable range of approaches to choose from. In the first place the key issues of empiricism and theory must be understood and addressed. Then there are the issues of positivism and phenomenology which have to be understood and resolved.

Within these contexts the researcher has then to choose a set of research tools which will help collect evidence, analyse evidence and produce findings.

Methodology choice is certainly a function of the topic being researched as well as the education of the reseacher and the culture and skills available in the institute. Compromises always have to be made and these may concern time and money.

The issues discussed in this article are not simple. They require an understanding of the nature of academic research and an ability to put these issues into a philosophical context. Some researchers find this view difficult to grasp and question why it is necessary. Where a doctor of philosophy (PhD) degree is being pursued the answer is in the title of the degree. To hold a $\mathrm{PhD}$ an individual should have his/her own philosophical stance towards their research clear in their mind. However, the same is still true for other doctorate degrees and even partly true for masters degrees. Perhaps this is actually true for any level of education?

\section{References}

Aguinis, H. 1993. 'Action research and scientific method: presumed discrepancies and actual similarities', Journal of Applied Behavioural Science, 29(4): 416-431.

Bell, J. 1987. Doing your research project. A guide for first-fime researchers in education and social science. United Kingdom: Open University Press.

Born, M. 1950. Cited in Margenau, H. The nature of physical reality. New York: McGraw-Hill.

Bynum, W., Browne, E. \& Porter, R. 1982. Dictionary of history of science. London: MacMillan Reference Books.

Cohen, L. \& Manion, L. 1987. Research methods in education. Second edition. London: Croom Helm.

Collins, H. \& Pinch, T. 1994. The golem. New York: Canto Cambridge University Press

Collins, H. 1994. Does science matter? - a broadcast video on science matters. United Kingdom: BBC, Open University.

Collopy, F. \& Armstrong, J. 1992. 'Expert opinions about extrapola tion and the mystery of the overlooked discontinuities', International Journal of Forecasting, 8(4): 575-182.

Creswell, J. 1994. Research design - qualitative \& quantitative approaches. London: Sage Publications 
Easterby-Smith, M., Thorpe, R. \& Lowe, A. 1994. Management research: an introduction. London: Sage Publications.

Einstein, A. 1950. Out of my later years. New York: Bonanza Books (Philosophical Library).

Freeman, J. 1992. 'Behind the smoke and mirrors: gauging the integrity of investment simulations', Financial Analysts Journal, 48(6): 26-31.

Galliers, R. 1991. Informations systems research. Henley-on Thames: Alfred Waller.

Glaser, B.G. \& Strauss, A.L. 1967. The discovery of grounded theory. Chicago: Aldine Inc.

Goldfisher, K. 1992. 'Modified Delphi: a concept for new product forecasting', Journal of Business Forecasting, 11(4): 10-11.

Gould, S.J. 1980. The panda's thumb. London: Norton and Co.

Jocher, C. 1928/29. 'The case method in social research', Social Forces Journal - MORE detail if possible please.

Kasanen, E. \& Suomi, R. 1987. 'The case method in information systems reseach', Liiketaloudellinen Aikakauskirja - Foretagsekonomisk (Finish Journal of Business Economics). Helsinki, Finland.

Kuhn, T. 1970. The structure of scientific revolutions. Chicago: University of Chicago Press.

Lakatos, I. 1970. 'Methodology of scientific research programmes'. In Lakatos, I. \& Musgrave, A. (eds.). Criticism and the growth of knowledge - proceedings of the International Colloquium in the Philosophy of Science. PLACE and publisher please, pp.100-101.

Ledford, G. \& Mohrman, S. 1993. 'Looking backward and forward at action research', Human Relations, 46(11): 1349-1359.

Lee. A. 1989. 'A scientific methodology for MIS case studies', MIS Quarterly, 13(1).

Leedy, P.D. 1989. Practical research-planning and designing. New York: MacMillan Publishing Company.

Maital, S. 1993. 'Oracles at work', Across the Board, 30(5): 52-53.

McCarthy, K. 1992. 'Comment on the "Analytic Delphi Method"', International Journal of Production Economics, 27(2): 135-136.

McKeon, R. \& Owen, D. (eds.). 1994. On knowing - the natural sciences. Chicago: University of Chicago Press.
Millar, R. 1994. Does science matter? - a broadcast video on science matters. United Kingdom: BBC, Open University.

Oppenheim, A.N. 1966. Questionnaire design and attitude measurement. New York: Gower.

Parsons, H. 1992. 'Hawthorne: an early OBM experiment', Journal of Organizational Behaviour Management, 12(1): 27-43.

Pascale, R. 1990. Managing at the edge. London: Penguin Books.

Pettigrew, A. 1985. 'Contextualist research: a natural way to link theory and practice'. In Lawler, E.E. (ed.). Doing research that is useful in theory and practice. San Francisco: Jossey Bass.

Popper, K. 1975. 'The rationality of scientific revolutions'. In Hacking, I. (ed.). Problems of scientific revolution: progress and ob. stacles to progress in the sciences. Oxford: Clarendon Press.

Reiman, M., Simon, B. \& Willie, J. 1992. 'Simterpolation: a simulation based interpolation approximation for queuing systems', Operations Research, 40(4): 706-723.

Remenyi, D. \& Williams, B. 1995. Some aspects of ethics and research into artificial intelligence -Working paper. Johannesburg: Department of Information Systems, University of the Witwatersrand.

Remenyi, D. 1990. Strategic information systems current practice and guidelines. Doctoral dissertation. United Kingdom: Henley Management College.

Smith, N. 1990. 'The case study: a useful reseacvh method for information management', Journal of Information Technology, 5: 123133.

Sutrick, K. 1993. 'Reducing the bias in empirical studies due to limit moves', Journal of Futures Markets, 13(5): 527-543.

Trundle, R. 1994. Ancient Greek philosophy: its development and relevance to our time. Brookfield: Ashgate.

Tung, L. \& Heminger, A. 1993. 'The effects of dialectical inquiry, devil's advocacy, and consensus inquiry methods in a GSS environment', Information and Management, 25(1): 33-41.

Wessley, S. 1994. Does science matter? - a broadcast video on science matters. United Kingdom: BBC, Open University.

Yin, R.K. 1989. Case study research - design and methods. London: Sage Publications. 